Article

\title{
Intercomparison of PurpleAir sensor performance over three years indoors and outdoors at a home: bias, precision, and limit of detection using an improved algorithm for calculating PM2.5
}

\author{
Lance Wallace ${ }^{1, *}$ \\ US EPA (retired) \\ 428 Woodley Way \\ Santa Rosa, CA 95409 \\ 1,* Correspondence: 1wallace73@gmail.com
}

\begin{abstract}
Low-cost particle sensors are now used worldwide to monitor outdoor air quality. However, they have only been in wide use for a few years. Are they reliable? Does their performance deteriorate over time? Are the algorithms for calculating PM2.5 provided by the Plantower company for PurpleAir monitors accurate? We investigate these questions using continuous measurements of four monitors (8 sensors) under normal conditions inside and outside a home for 1.5-3 years. A recently-developed algorithm (called ALT-CF3) is compared to the two existing Plantower algorithms. The Plantower CF1 algorithm was shown to lose $25-50 \%$ of all indoor data due to the questionable practice of assigning zero to all concentrations below a threshold. None of these data were lost using the ALT-CF3 algorithm. About $92 \%$ of all data showed precision better than $20 \%$ using the ALT-CF3 algorithm, but only about $45-75 \%$ of data achieved that level using the Plantower CF1 algorithm. The limits of detection (LODs) using the ALT-CF3 algorithm were mostly under $1 \mathrm{ug} / \mathrm{m} 3$, compared to about 3-10 ug/m3 using the Plantower CF1 algorithm. The percent of observations exceeding the LOD was 53-92\% for the ALT-CF3 algorithm, but only 16-44\% for the Plantower CF1 algorithm. For indoor air in homes, the Plantower algorithms are inappropriate.
\end{abstract}

Keywords: low-cost particle monitors, PurpleAir, PM2.5, bias, precision, limit of detection, Plantower, PMS-5003 sensors

\section{Introduction}

Over the last few years, a revolution in developing small low-cost particle sensors has occurred. The sensors have been evaluated in multiple laboratory studies [1-6]. Their behavior in outdoor sites has also been studied extensively [7-12]). The US Environmental Protection Agency has provided guidance on their use in outdoor settings [13-14]. However, fewer studies have focused on their use indoors [15-21].

Indoor studies are particularly relevant, since most people spend most of their time indoors [22-23]. Until now, most epidemiology studies have been able to use only outdoor measurements to estimate human exposure; indoor exposures may or may not be estimated, but there are seldom any measured data [24-26]. Some studies such as the Harvard 6-City Study or EPA's Particle TEAM study have been able to use personal and indoor monitors to provide an estimate of the total personal or indoor exposure to particles [27-32]. However, these studies have been limited to relatively short-term exposures because of the expense of acquiring, setting up, and taking down expensive researchgrade instruments in homes.

Now it has finally become possible to determine long-term exposure to particles, since the new sensors are normally quiet and inconspicuous and can operate continuously without the need to maintain, clean, or manually download the data they collect. Downloading is made particularly easy by the PurpleAir company, which maintains a Web-accessible database of all data except that for users who have requested privacy.

The overriding concern in using low-cost particle sensors is their reliability and accuracy. Accuracy is a function of bias and precision. However, bias can be corrected; precision cannot. 
The manufacturer of the PMS 5003 sensors used in PurpleAir PA-II monitors is the Plantower company (Plantower.com). Plantower employs two proprietary algorithms (CF1 and CF_ATM) to estimate PM2.5. For PM2.5 concentrations less than about $28 \mathrm{ug} / \mathrm{m} 3$, which constitute the vast majority of measured concentrations in many developed nations, the two algorithms give identical results [32]. Plantower provides no information about the composition or indeed the very existence of a calibration aerosol. Nor does the company provide any other data about the calculations involved in translating observed numbers of particles in six size categories into a mass concentration estimate. We have shown how both these algorithms are seriously flawed. We developed a transparent and reproducible algorithm (ALT-CF3) that was shown to outperform the Plantower algorithms with respect to bias, precision, limit of detection (LOD), and distribution fitting [32]. Our results suggest that the Plantower algorithms overestimate PM2.5 concentrations by about $40-50 \%$, as has been found by other investigations. However, this bias can be corrected. What is much more serious is the Plantower problem with precision.

We show in this paper that estimates of precision may be severely impacted by the flawed Plantower practice of assigning a value of zero to concentrations not reaching a certain predefined threshold. In particular, we show that indoor concentrations in a home with reasonably typical indoor activities such as cooking, cleaning, and other particleproducing activities fall below this threshold for such a large fraction of time that estimates of both precision and PM2.5 concentration are limited to a greatly reduced fraction of all observations. .

PurpleAir PA-II monitors include two independent Plantower PMS 5003 sensors which we identify as $a$ and $b$. We define precision for each monitor as the absolute difference between the PM2.5 readings divided by their sum: abs( $a$ $b) /(a+b)$. The monitors employed in this study are identified by the numbers 1-4. For example, the two sensors in monitor 1 are identified as $1 \mathrm{a}$ and $1 \mathrm{~b}$.

\section{Materials and Methods}

All data were collected inside or outside a home with two residents. The indoor PurpleAir monitors were placed on a desk or dresser about $1.6 \mathrm{~m}$ high. The outdoor monitor was hung about $2 \mathrm{~m}$ high from a bracket about $15 \mathrm{~cm}$ from the home. The home is a detached 1-story building of about $400 \mathrm{~m}^{3}$ volume located in the city of Santa Rosa, CA. Heating is supplied by a natural gas furnace, and the temperature is normally set to $72{ }^{\circ} \mathrm{F}\left(22{ }^{\circ} \mathrm{C}\right)$. A gas stove and electric oven are used for cooking on about 5 or 6 days a week. A central air conditioner is used at times in the summer. The central fan is normally on and the main filter is equipped with electrically charged wires to attract particles. The air exchange rate of the home was measured on multiple occasions and was generally in the range from 0.2 to 0.3 air changes per hour. Two blower door tests confirmed that the home was well constructed. Windows are normally closed except in summer when the air conditioner is not being used. Some experiments were done in a closed room involving single puffs from a vaping pen containing marijuana liquid. These experiments resulted in increased PM2.5 levels for less than $4 \%$ of the time.

\section{Results and Discussion}

Monitors 1 and 2 collected data for 3 years. Monitor 1 was indoors the entire time; monitor 2 was indoors for 2 years and outdoors for 1 year. A total of 829,907 observations were made; some were 80-second averages, most were 2minute averages. Only the ALT-CF3 values with a precision better than $20 \%$ (under 0.2 ) were accepted. This left $92 \%$ of the data (763,102 observations).

Monitors 3 and 4 collected data over the last 18 months of the study (6/18/2020 to 1/14/2022). Monitor 3 was outdoors for all but one month; monitor 4 was indoors the entire time. There were 406,310 observations total, and 370,906 observations remained after limiting the data to those with a precision under 0.2 .

The PM2.5 measurements for all monitors and both time periods are supplied in Tables S1 and S2 in the Supporting Information (SI). Mean indoor PM2.5 values ranged from 3.6 to $5.7 \mathrm{ug} / \mathrm{m} 3$. These values are quite 
comparable to those found in a previous study including 91 PurpleAir indoor monitors averaged over times from 796 hours to 13,564 hours. The observed means ranged from a median of $3.4 \mathrm{ug} / \mathrm{m} 3$ to a $75^{\text {th }}$ percentile value of $5.5 \mathrm{ug} / \mathrm{m} 3$ [15].

\subsection{Relative Bias}

The bias relative to the mean of ALT-CF3 estimates of PM2.5 (ug/m3) for sensors $a$ and $b$ for all pairs of sensors was calculated for the final 18-month period when all 4 monitors ( 8 sensors) were operating. The mean (SE) overall bias was $3.00 \%(0.7 \%)$ ranging from $0.5 \%$ to $5 \%$ (Table 1$)$.

Table 1. Mean PM2.5 concentrations (ug/m3) and relative bias for the ALT-CF3 algorithm.

\begin{tabular}{|l|r|r|r|r|r|}
\hline & N obs. & Mean & SE & RSE & Bias \\
\hline 1a PM2.5 CF3 IN & 353256 & 3.38 & 0.016 & 0.0049 & 1.031 \\
\hline 1b PM2.5 CF3 IN & 353256 & 3.18 & 0.015 & 0.0049 & 0.969 \\
\hline Mean 1 CF3 IN & 353256 & 3.28 & 0.023 & 0.0069 & \\
\hline 4a PM2.5 CF3 IN & 353256 & 3.65 & 0.018 & 0.0049 & 0.970 \\
\hline 4b PM2.5 CF3 IN & 353256 & 3.88 & 0.019 & 0.0048 & 1.030 \\
\hline Mean 4 CF3 IN & 353256 & 3.77 & 0.026 & 0.0068 & \\
\hline 2a PM2.5 CF3 IN & 117804 & 3.31 & 0.018 & 0.0054 & 0.953 \\
\hline 2b PM2.5 CF3 IN & 117804 & 3.64 & 0.020 & 0.0055 & 1.047 \\
\hline Mean 2 CF3 IN & 117804 & 3.48 & 0.027 & 0.0077 & \\
\hline 2a PM2.5 CF3 OUT & 242663 & 4.82 & 0.020 & 0.0042 & 0.995 \\
\hline 2b PM2.5 CF3 OUT & 242663 & 4.87 & 0.021 & 0.0043 & 1.005 \\
\hline Mean 2 CF3 OUT & 242663 & 4.85 & 0.029 & 0.0060 & \\
\hline 3a PM2.5 CF3 OUT & 356484 & 5.54 & 0.022 & 0.0039 & 0.965 \\
\hline 3b PM2.5 CF3 OUT & 356484 & 5.94 & 0.023 & 0.0039 & 1.035 \\
\hline Mean 3 OUT CF3 & 356484 & 5.74 & 0.032 & 0.0056 & \\
\hline
\end{tabular}

The same calculations of bias for the Plantower CF1 algorithm resulted in the loss of more than 100,000 observations for the indoor monitors 1 and 4 due to the large number of reported zeros for the PM2.5 observations. Monitor 2 both indoors and outdoors lost about 50\% of all observations. Monitor 3 lost more than 75,000 observations (Table 2).

There was also an effect of increased mean values even beyond the $40 \%$ increase often noted for the Plantower CF1 algorithm. The mean indoor values were about 100\% higher than for the ALT-CF3 algorithm, and the mean outdoor values were more than $200 \%$ higher. The mean (SE) overall bias was $4.0 \%(1.5 \%)$ ranging from $0.6 \%$ to $8.2 \%$. These bias calculations are only slightly worse for the Plantower CF1 algorithm, because they are "helped" by not having to consider the thousands of deleted observations which would otherwise lead to different (probably higher) estimates of bias. 
Table 2. Mean PM2.5 concentrations and relative bias for the Plantower CF1 algorithm

\begin{tabular}{|l|r|r|r|r|r|}
\hline & N obs & Mean & SE & RSE & Bias \\
\hline 1a PM2.5_CF1 IN & 242553 & 7.07 & 0.040 & 0.0056 & 1.012 \\
\hline 1b PM2.5_CF1 IN & 242553 & 6.90 & 0.040 & 0.0058 & 0.988 \\
\hline Mean 1 CF1 IN & 242553 & 6.98 & 0.057 & 0.0081 & \\
\hline 4a PM2.5_CF1 IN & 240097 & 7.54 & 0.043 & 0.0057 & 0.937 \\
\hline 4b PM2.5 CF1 IN & 240097 & 8.55 & 0.049 & 0.0057 & 1.063 \\
\hline Mean 4 CF1 IN & 240097 & 8.05 & 0.065 & 0.0080 & \\
\hline 2a PM2.5_CF1 IN & 64344 & 8.59 & 0.056 & 0.0066 & 0.994 \\
\hline 2b PM2.5_CF1 IN & 64344 & 8.70 & 0.060 & 0.0069 & 1.006 \\
\hline Mean 2 CF1 IN & 64344 & 8.65 & 0.082 & 0.0095 & \\
\hline 2a PM2.5_CF1 OUT & 129081 & 14.00 & 0.067 & 0.0048 & 1.038 \\
\hline 2b PM2.5_CF1 OUT & 129081 & 12.98 & 0.068 & 0.0053 & 0.962 \\
\hline Mean 2 CF1 OUT & 129081 & 13.49 & 0.096 & 0.0071 & \\
\hline 3a PM2.5_CF1 OUT & 278256 & 10.48 & 0.045 & 0.0043 & 0.918 \\
\hline 3b PM2.5_CF1 OUT & 278256 & 12.35 & 0.054 & 0.0044 & 1.082 \\
\hline Mean 3 CF1 OUT & 278256 & 11.41 & 0.070 & 0.0061 & \\
\hline
\end{tabular}

The absolute bias of these four monitors with respect to regulatory FEM or FRM monitors could not be determined, since no regulatory monitor was close. However, a previous study compared 33 PurpleAir outdoor monitors to 27 nearby regulatory monitors [32]. The bias (ratio of PurpleAir monitor PM2.5 using the CF3 calibration to regulatory monitor PM2.5) had a median value of 0.96 (IQR 0.77 to 1.21).

\subsubsection{Comparison with FEM bias}

The US EPA operates a program determining the bias of selected Federal Equivalent Method (FEM) PM2.5 results by setting up a side-by-side gravimetric monitor employing the Federal Reference Method (FRM) https://www.epa.gov/outdoor-air-quality-data/pm25-continuous-monitor-comparability-assessments. The bias of the continuous FEM monitor with respect to the collocated FRM monitor is calculated over a 3-year period. A sample of 61 reports from the state of CA showed a mean absolute bias of 20.5\% (SE 3.2\%) for the FEM monitor compared to the FRM monitor. 41 of the calculated biases were positive, with a mean (SE) of $+27.3 \%$ (4.5\%.). The median bias was 1.21 (IQR 1.04 to 1.25). These results suggest that the range of the absolute bias of 33 PurpleAir monitors employed in [32] using the CF3 algorithm appears comparable to the absolute bias of the 61 FEM monitors compared to FRM monitors in the EPA comparability assessments.

\subsection{Precision}

For the entire 3-year period, median precision for monitors 1 and 2 was between $4.6 \%$ and $5.7 \%$ using the ALTCF3 algorithm (Table 3). The Plantower CF1 median precision for the same data ranged between $8.4 \%$ and $20.5 \%$ with, however, more than 100,000 fewer measurements for monitor 1 and 50,000 fewer for monitor 2 due to the excessive number of zeros reported by the CF1 algorithm. Applying the precision cutoff of 0.2 for the Plantower CF1 measurements resulted in an additional loss of $25 \%$ of the remaining data for monitor 1 and $45-50 \%$ of the remaining data for monitor 2. Overall, the loss of data using the Plantower CF1 algorithm amounted to 277,488 (36\%) measurements for Monitor 1 and 387,991 (51\%) of all measurements for monitor 2. 
Table 3. Precision compared using ALT-CF3 and Plantower CF1 algorithms. Time period: 1/10/2019 to 1/14/2022.

\begin{tabular}{|c|c|c|c|c|c|c|c|c|}
\hline & $\begin{array}{l}\text { Valid } \\
\mathrm{N}\end{array}$ & Mean & Std. Err. & $\begin{array}{l}\text { Lower } \\
\text { Quartile }\end{array}$ & Median & $\begin{array}{l}\text { Upper } \\
\text { Quartile }\end{array}$ & 90th \%tile & Max \\
\hline \multicolumn{9}{|c|}{ ALT-CF3 algorithm (using precision cutoff of 0.2) } \\
\hline Monitor 1 indoors & 763102 & 0.064 & 0.000055 & 0.025 & 0.053 & 0.094 & 0.14 & 0.2 \\
\hline Monitor 2 indoors & 499296 & 0.067 & 0.000068 & 0.027 & 0.057 & 0.097 & 0.14 & 0.2 \\
\hline Monitor 2 outdoors & 242663 & 0.058 & 0.000093 & 0.021 & 0.046 & 0.084 & 0.13 & 0.2 \\
\hline \multicolumn{9}{|c|}{ Plantower CF1 algorithm (using ALT-CF3 cutoff of 0.2) } \\
\hline Monitor 1 indoors & 647757 & 0.192 & 0.000334 & 0.034 & 0.084 & 0.20 & 0.57 & 1 \\
\hline Monitor 2 indoors & 448867 & 0.337 & 0.000495 & 0.072 & 0.205 & 0.51 & 1 & 1 \\
\hline Monitor 2 outdoors & 234814 & 0.293 & 0.000631 & 0.065 & 0.172 & 0.41 & 0.92 & 1 \\
\hline \multicolumn{9}{|c|}{ Plantower CF1 algorithm (using precision cutoff of 0.2) } \\
\hline Monitor 1 indoors & 486614 & 0.067 & 0.000074 & 0.025 & 0.055 & 0.10 & 0.15 & 0.2 \\
\hline Monitor 2 indoors & 224877 & 0.081 & 0.000118 & 0.033 & 0.071 & 0.13 & 0.17 & 0.2 \\
\hline Monitor 2 outdoors & 129081 & 0.082 & 0.000157 & 0.033 & 0.073 & 0.13 & 0.17 & 0.2 \\
\hline
\end{tabular}

For the 18-month second period employing monitors 3 and 4, the loss of data due to employing the CF1 algorithm was similar for the indoor data at 33\%, but improved for the outdoor data (20\%) (Table S3).

\subsection{PM2.5 concentrations of zero}

From the 3-year and 18-month studies, the Plantower CF1 algorithm reported PM2.5 concentrations of zero for about 60,000 to 160,000 indoor measurements (12\% to $23 \%$ of the total) and 10,000 to 35,000 outdoor measurements (4$14 \%$ of the total) (Table 4). The ALT-CF3 algorithm, by contrast, reports no concentrations of zero for the same set of observations. This is because there are never occasions when the number of particles in the smallest size category (0.3$0.5 \mathrm{um}$ ) fall to zero.

Table 4. Number of PM2.5 concentrations reported as zero by the Plantower CF1 algorithm for monitors 1 \& 2 over a 3-year period and monitors $3 \& 4$ over an 18-month period

\begin{tabular}{|l|l|r|r|r|}
\hline Sensor & Location & N obs. & \# zeros & fraction $=0$ \\
\hline $1 \mathrm{a}$ & Indoors & 815558 & 165732 & 0.20 \\
\hline $\mathrm{1b}$ & Indoors & 817696 & 164399 & 0.20 \\
\hline $\mathrm{2a}$ & Indoors & 530781 & 63867 & 0.12 \\
\hline $\mathrm{2b}$ & Indoors & 558322 & 130263 & 0.23 \\
\hline $4 \mathrm{a}$ & Indoors & 406059 & 61444 & 0.15 \\
\hline $4 \mathrm{~b}$ & Indoors & 406068 & 69435 & 0.17 \\
\hline $2 \mathrm{a}$ & Outdoors & 252532 & 10324 & 0.04 \\
\hline $\mathrm{2b}$ & Outdoors & 253439 & 35374 & 0.14 \\
\hline $3 \mathrm{a}$ & Outdoors & 363786 & 23516 & 0.06 \\
\hline $3 \mathrm{~b}$ & Outdoors & 363783 & 18757 & 0.05 \\
\hline
\end{tabular}

The prevalence of zeros in indoor data, ranging from $12 \%-23 \%$ of the observations, is due entirely to the Plantower decision to define all values below a certain cutoff as zero. This loss of data will be impossible to recover for all 
investigators using either of the Plantower CF1 and CF_ATM algorithms. Statisticians do not approve replacing concentrations below the LOD with zero, the LOD itself, or half the LOD [33]. In this case, the cutoff, at $0.01 \mathrm{ug} / \mathrm{m} 3$, is in fact far below the LOD.

\subsection{Variation of precision over time}

Table 5. Variation of precision over time for monitors $1 \& 2$ (3 years) and $3 \& 4$ (18 months)

\begin{tabular}{|c|c|c|c|c|c|c|}
\hline \multirow[b]{2}{*}{ Monitor } & \multicolumn{3}{|c|}{ 3-year period $(1 / 10 / 19$ to $1 / 14 / 22)$} & \multicolumn{3}{|c|}{$18-$ month period $(6 / 18 / 20$ to $1 / 14 / 22)$} \\
\hline & $1 \mathrm{IN}$ & $2 \mathrm{IN}$ & 2 OUT & 3 OUT & $3 \mathrm{IN}$ & $4 \mathrm{IN}$ \\
\hline Location & Indoors & Indoors & Outdoors & Outdoors & Indoors & Indoors \\
\hline $\mathrm{N}$ & 763102 & 499296 & 242663 & 356484 & 42204 & 370906 \\
\hline Intercept & -0.28 & -0.33 & 0.61 & -0.27 & 1.6 & 0.1 \\
\hline SE (Int.) & 0.007 & 0.010 & 0.040 & 0.019 & 0.039 & 0.022 \\
\hline Slope & $7.8 \mathrm{E}-06$ & $9.0 \mathrm{E}-06$ & $-1.2 \mathrm{E}-05$ & $7.4 \mathrm{E}-06$ & $-3.4 \mathrm{E}-05$ & $-8.7 \mathrm{E}-07$ \\
\hline SE (slope) & 1.7E-07 & 2.3E-07 & 9.1E-07 & 4.3E-07 & 8.8E-07 & 4.8E-07 \\
\hline $\mathrm{R}^{2}$ (adj.) & 0.0028 & 0.00319 & 0.00076 & 0.00082 & 0.034 & 0.00006 \\
\hline SE of estimate & 0.048 & 0.048 & 0.046 & 0.042 & 0.032 & 0.050 \\
\hline F-value & 2181 & 1599 & 186 & 296 & 1500 & 3.2 \\
\hline z & 47 & 40 & -14 & 17 & -39 & -2 \\
\hline $\mathrm{p}$-value & 0 & 0 & 0 & 0 & 0 & 0.072 \\
\hline starting precision & 0.060 & 0.062 & 0.083 & 0.054 & 0.058 & 0.068 \\
\hline ending precision & 0.068 & 0.072 & 0.070 & 0.058 & 0.038 & 0.067 \\
\hline $\begin{array}{l}\text { Relative } \quad \text { annual } \\
\text { increase (\%) }\end{array}$ & 4.8 & 5.3 & -5.3 & 5.3 & -22.6 & -0.49 \\
\hline
\end{tabular}

\subsection{Limit of detection ( $L O D$ )}

A definition for the LOD for the case of analyzing a physicochemical sample can be found in many publications (e.g., [34]). The definition envisions analyzing several samples expected to have concentrations near the LOD. If the results of analyzing the several samples shows that the mean is more than 3 times the standard deviation, then the mean value is considered to be near (somewhat above) the LOD.

For the case of continuous sampling, a different definitionis needed. One approach was advanced in [18]. In this definition, the LOD occurs at the lowest mean value $\mu$ above which more than $95 \%$ of mean values exceed their standard deviations $\sigma$ by more than a factor of $3(\mu / \sigma>3)$. In practice, this requires identifying all cases with $\mu / \sigma<3$, sorting according to $\mu$ ascending, and then counting the number of cases with $\mu / \sigma<3$ in, say, blocks of 100 in ascending order. When a block of 100 is reached with fewer than $5 \mu / \sigma$ values $<3$, a candidate for the LOD has been found within that block. However, further exploration at higher mean concentrations may show a new block of 100 with 5 or more cases of $\mu / \sigma<3$, at which point that new block of 100 now contains a new (higher) candidate for the LOD. The search ends when all the data have been explored, but in practice it ends much earlier, when there are increasingly great "distances" between blocks of 100 with 5 or more values of $\mu / \sigma<3$.

LODs were determined for all four monitors. For monitor 2, which spent time indoors and outdoors, the LOD was calculated separately. The LODs calculated for the ALT-CF3 algorithm ranged from 0.6 to $1.3 \mathrm{ug} / \mathrm{m} 3, \mathrm{compared}$ to 2.9 to $9.9 \mathrm{ug} / \mathrm{m} 3$ for the Plantower CF1 algorithm (Table 6). About 53-92\% of the data exceeded the CF3 LODs, but only $16-44 \%$ of the data exceeded the Plantower CF1 LODs. 
Table 6. PM2.5 LODs (ug/m3) calculated for the ALT-CF3 and Plantower CF1 algorithms. Number and percent of observations greater than the LOD.

\begin{tabular}{|r|l|r|r|r|r|r|r|r|}
\hline Sensor & Location & Valid N & $\begin{array}{r}\text { CF3 } \\
\text { LOD }\end{array}$ & CF3 >LOD & CF3 \%>LOD & $\begin{array}{r}\text { CF1 } \\
\text { LOD }\end{array}$ & CF1 >LOD & CF1 \%>LOD \\
\hline 1 & Indoors & 406108 & 0.99 & 233900 & 58 & 2.9 & 177908 & 44 \\
\hline 2 & Outdoors & 253454 & 0.92 & 203384 & 80 & 9.9 & 39487 & 16 \\
\hline 2 & Indoors & 146229 & 0.72 & 110674 & 76 & 3.2 & 44289 & 30 \\
\hline 3 & Outdoors & 363797 & 0.6 & 334973 & 92 & 4.4 & 156850 & 43 \\
\hline 4 & Indoors & 406092 & 1.32 & 215872 & 53 & 5.3 & 79371 & 20 \\
\hline
\end{tabular}

\section{Conclusions}

At typical levels of both indoor and outdoor PM2.5, the Plantower CF1 and CF_ATM algorithms lose an unacceptably large fraction of observations due to the choice of setting a threshold below which observations are assigned a value of zero. This practice is not supported by statistical theory. It causes the loss of substantial amounts of data (12-23\% in our three-year study). It also increases the already high overestimates of PM2.5 due to deleting lower concentrations. No models employing either of the two Plantower algorithms can restore these values. The ALT-CF3 algorithm loses no data, since it depends on particle counts that never go to zero. The ALT-CF3 algorithm also has improved bias, precision, and limits of detection.

Mean precision using the $\mathrm{CF} 3$ algorithm is good at 6-7\%. Although the precision of the Plantower $\mathrm{CF} 1$ alogorithm is not much worse at about $7-8 \%$, there is a very great loss of data due to the unscientific choice to substitute zero for all values below a certain threshold. Similarly, the relative bias of 2 sensors in the same monitor was not greatly worse for the Plantower CF1 algorithm than for the ALT-CF3 algorithm ( $4 \%$ compared to $\sim 3 \%$ ), but again the loss of data was in the hundreds of thousands of observations.

With respect to the LOD, here there was a very large difference between the two algorithms, with the LODs for the Plantower CF1 algorithm so high that more than half of all data (56-84\%) was below the LOD. By contrast, the ALT-CF3 algorithm resulted in more than half of all data (53-92\%) above the LOD.

It is concluded that the Plantower algorithms CF1 and CF_ALT are not suitable for measuring typical PM2.5 concentrations in homes, or low ambient concentrations. The ALT-CF3 algorithm, available on the PurpleAir API site, is the only one there that does not depend on the Plantower proprietary algorithms.

\section{References}

1. AQ-SPEC (2016). Field evaluation PurpleAir PM sensor. http://www.aqmd.gov/docs/default-source/aq-spec/fieldevaluations/purpleair---field-evaluation.pdf.

2. He, M., Kuerbanjiang, N., \&Dhaniyala, S.. Performance characteristics of the low-cost Plantower PMS optical sensor. Aerosol Sci Tech 2020, 54 (2):232-241. doi: 10.1080/02786826.2019.1696015.

3. Kelly, K.E.; Whitaker, J.; Petty, A.,; Widmer, C.; Dybwad, A.; Sleeth, D.; Martin, R.; Butterfield, A. Ambient and laboratory evaluation of a low-cost particulate matter sensor. Environmental Pollution 2017, 221:491-500

4. Singer, B. C.; Delp, W.W. . Response of consumer and research grade indoor air quality monitors to residential sources of fine particles. Indoor Air 2018, 28:624-639. https://doi.org/10.1111/ina.12463 Accessed Dec. 19, 2020.

5. Tryner, J.; Quinn, C.; Windom, B. C.; Volckens, J. Design and evaluation of a portable PM2.5 monitor featuring a lowcost sensor in line with an active filter sampler. Environmental Science Processes and Impacts 2019, 21:1403-15. 
6. Wang, Z.; Delp, W. W.; Singer, B.C. Performance of low-cost indoor air quality monitors for PM2.5 and PM10 from residential sources. Building and Environment 2020, https://doi.org/10.1016/j.buildenv.2020.106654. (Accessed 2/2/22).

7. Bi, J.; Wildani, A.; Chang, H. H.; Liu, Y. Incorporating low-cost sensor measurements into high-resolution PM2.5 modeling at a large spatial scale. Environmental Sci Tech 2020, 54, 4, $2152-2162$. https://pubs.acs.org/doi/10.1021/acs.est.9b06046 Accessed Jan. 9, 2022.

8. Gupta, P.; Doraiswamy, P.; Levy, R.; Pikelnaya, O.; Maibach, J.; Feenstra, B.; et al. (2018). Impact of California fires on local and regional air quality: The role of a low-cost sensor network and satellite observations. Geo Health 2018, 2, 172181. https://doi.org/10.1029/2018GH000136 Accessed Dec. 18, 2020.

9. Levy Zamora, M.; Xiong, F.; Gentner, D.; Kerkez, B.; Kohrman-Glaser, J.; Koehler, K. (2018). Field and laboratory evaluations of the low-cost Plantower particulate matter sensor. Environmental Sci Tech 2018, 53 (2), 838-49.

10. Magi, B.I.; Cupini, C.; Francis, J.; Green, M.; Hauser, C. Evaluation of PM2.5 measured in an urban setting using a low-cost optical particle counter and a Federal Equivalent Method Beta Attenuation Monitor. Aerosol Sci Tech 2019, 54:147-159. doi:10.1080/02786826.2019.1619915.

11. Sayahi, T.; Butterfield, A.; Kelly, K.E. Long-term field evaluation of the Plantower PMS low-cost particulate matter sensors. Environmental Pollution 2019, 245:932-940.

12. Zusman, M.; Schumacher, C.S.; Gassett, A. J.; Spalt, E.W.; Austin, E.; Larson, T.V.; Arvlin, G. C.; Seto, E.; Kaufman, J.D.; Sheppard, L. (2020). Calibration of low-cost particulate matter sensors: Model development for a multi-city epidemiological study. Environment International 2020,134:105329.

13. US EPA (2017) https://www.epa.gov/air-sensor-toolbox/how-use-air-sensors-air-sensor-guidebook

14. Williams, R.; Vasu, K.; Snyder, E.; Kaufman, A.; Dye, T.; Rutter, A.; Russell, A.; Hafner, H. Air Sensor Guidebook. U.S. Environmental Protection Agency, Washington, DC, 2014.EPA/600/R-14/159 (NTIS PB2015-100610).

15. Bi, J.; Wallace, L.; Sarnat, J.A.; Liu, Y. Characterizing outdoor infiltration and indoor contribution of PM2.5 with citizen-based low-cost monitoring data. Environmental Pollution 2021 276:116793.

16. Kaduwela, A. P.; Kaduwela, A.P.; Jrade, E.; Brusseau, M.; Morris, S.; Morris, J.; Risk, V. Development of a low-cost air sensor package and indoor air quality monitoring in a California middle school: Detection of a distant wildfire. Journal Air Waste Manage Assoc 2019, 69 (9):1015-1022. doi:10.1080/10962247.2019.1629362

17. Klepeis, N.E.; Bellettiere, J.; Hughes, S.C.; Nguyen, B.; Berardi, V.; Liles, S.; et al. Fine particles in homes of predominantly low-income families with children and smokers: Key physical and behavioral determinants to inform indoor-air-quality interventions. PLoS ONE 2017, 12(5): e0177718. https://doi.org/10.1371/journal.pone.0177718

18. Wallace, L. A.; Wheeler, A.; Kearney, J., Van Ryswyk, K.; You, H.; Kulka, R.; Rasmussen, P.; Brook, J.; Xu, X. Validation of continuous particle monitors for personal, indoor, and outdoor exposures. Journal of Exposure Science and Environmental Epidemiology 2010, 21:49-64.

19. Wallace, L.A.; Ott, W.R.; Zhao, T.; Cheng, K-C; Hildemann, L. (2020). Secondhand exposure from vaping marijuana: Concentrations, emissions, and exposures determined using both research-grade and low-cost monitors. Atmospheric Environment: X 2020, 8 100093. https://www.sciencedirect.com/science/article/pii/S2590162120300332?via\%3Dihub Accessed Jan. 9, 2022. 
20. Wang, K.; Chen, F. E.; Au, W.; Zhao, Z.; Xia, Z-L. Evaluating the feasibility of a personal particle exposure monitor in outdoor and indoor microenvironments in Shanghai, China. International Journal of Environmental Health Research 2019, 29:209-20. doi:10.1080/09603123.2018.1533531.

21. Zheng, T.; Bergin, M. H.; Johnson, K. K.; Tripathi, S. N.; Shirodkar, S.; Landis, M. S.; Sutaria, R..; Carlson, D. E. (2018). Field evaluation of low-cost particulate matter sensors in high-and low-concentration environments. Atmospheric Measurement Techniques 2018,11 (8), 4823-4846. doi.org/10.5194/amt-11-4823-2018. https://amt.copernicus.org/articles/11/4823/2018/ (Accessed 2/2/22).

22. Klepeis N.; Tsang A.; Behar JV. 1995. Analysis of the National Human Activity Pattern Study (NHAPS) Respondents from a Standpoint of Exposure Assessment. Final Report, Contract \#68-01-7325. US EPA. Las Vegas, NV, USA. 1995.

23. Klepeis, N.E.; Nelson, W.C.; Ott, W.R.; Robinson, J.; Tsang, A.M.; Switzer, P.; Behar J.V.; Hern, S.; Engelmann, W. (2001). The National Human Activity Pattern Survey (NHAPS): a resource for assessing exposure to environmental pollutants. J Expo Anal Environ Epidemiol 2001, 11(3):231-252.

24. Apte, J.S.; Brauer, M.; Cohen, A.J.; Ezzati, M..; Pope, C.A. III. Ambient PM2.5 Reduces Global and Regional Life Expectancy. Env. Sci. Tech Letters 2018,5, 546-551.

25. Cohen, A. J.; Brauer, M.; Burnett, R.; Anderson, H. R.; Frostad, J.; Estep, K.; Balakrishnan, K.; Brunekreef, B.; Dandona, L.; Dandona, R.; et al. Estimates and 25-year trends of the global burden of disease attributable to ambient air pollution: an analysis of data from the Global Burden of Diseases Study 2015. Lancet 2017, 389, 1907-1918.

26. Hystad, P.; Larkin, A.; Rangarajan, S.; Al Habib, K.F.; Avezum, Á.; Calik, K.B.T.; Chifamba, J.; Dans, A.; Diaz, R.; du Plessis, J.L.; et al. Associations of outdoor fine particulate air pollution and cardiovascular disease in 157436 individ0uals from 21 high-income, middle-income, and low-income countries (PURE): A prospective cohort study. Lancet Planet. Health 2020, 4, e235-e245.

27. Dockery, D.W.; Pope, C.A.; Xu, X.; Spengler, J.D.; Ware, J.H.; Fay, M.E.; Ferris, B.G.; Speizer, F.E. An Association between Air Pollution and Mortality in Six U.S. Cities. N. Engl. J. Med. 1993, 329, 1753-1759.

28. Özkaynak, H.; Xue, J.; Spengler, J.; Wallace, L.; Pellizzari, E; Jenkins, P. Personal exposure to airborne particles and metals: results from the Particle TEAM study in Riverside, California. Expo Anal Environ Epidemiol 1996;6(1):57-78.

29. Kearney, J.; Wallace, L.; MacNeill, M.; Xu, X.; Van Ryswyk, K..; You, H.. Kulka, R.; Wheeler, A. Residential indoor and outdoor ultrafine particles in Windsor, Ontario, Atmospheric Environment, 2011 40, 7583-7593.

30. Wallace, L.; Williams, R.; Suggs, J.; et al. Exposure of high-risk subpopulations to particles: final report-APM-21. US EPA, National Exposure Research Laboratory, Research Triangle Park, NC. EPA/600/R-03/145. 2003.

31. Wallace, L.; Williams, R.; Suggs, J. et al. Estimating contributions of outdoor fine particles to indoor concentrations and personal exposures: effects of household and personal activities. APM-214. Office of Research and Development Research Triangle Park, NC, 27711 EPA 600/R-06/023. March 2006.

32. Wallace, L.; Bi, J.; Ott, W.R.; Sarnat, J.A.; Liu, Y. Calibration of low-cost PurpleAir outdoor monitors using an improved method of calculating $\mathrm{PM}_{2.5}$. Atmospheric Environment 2021, 256, 118432. https://www.sciencedirect.com/science/article/abs/pii/S135223102100251X (Accessed 2/2/22).

33. Helsel, D. Much ado about next to nothing: Incorporating nondetects in science. Annals of Occup Hygiene 2010, 54 (3):257-262. 
34. International Organization for Standardization (ISO). Capability of Detection; Report No. ISO 11843-1; ISO: Geneva, Switzerland, 1997. 